\title{
Study on the Influencing Factors of Migrant Workers' Housing Choices
}

\author{
Jingcai Zhang \\ Tianjin University of Commerce \\ Tianjin, China
}

\begin{abstract}
Migrant workers in the choice of housing, their housing choices will be affected by a variety of factors and constraints. In this paper, the migrant workers housing choices were analyzed, and then pointed out the factors that affect the choice of housing workers, and finally put forward measures to improve the housing conditions of migrant workers. The purpose is to provide some relevant suggestions for the housing problems of migrant workers as well as to provide a reference for the government to formulate relevant policies.
\end{abstract}

Keywords-migrant workers; housing choice; influencing factors

\section{INTRODUCTION}

In the process of urbanization and urbanization in China, migrant workers play a very important role, and make great contributions to urban construction and social development. However, when China's urbanization and urbanization level increased year by year, a large group of migrant workers did not keep up with the pace of urbanization. From the overall point of view, the housing situation of migrant workers in China is not optimistic, the living area is relatively small, the quality of living is relatively poor, and so on. This poor housing situation is one of the performance of migrant workers in half of the city, is also an important obstacle to migrant workers into the urban community, so the settlement of the housing problem of migrant workers is particularly important. To improve the housing conditions of migrant workers, it is necessary to provide suitable housing for migrant workers and supporting measures.

\section{MIGRANT WORKERS IN THE FORM OF HOUSING}

According to the current situation of China's migrant workers housing, migrant workers housing basically divided into: simple shed, individual or collective dormitory, and flat-share, visiting relatives and friends since there are very few buyers. For most migrant workers, they live in the form of staff dormitory based, the cost of living in these places is generally relatively low, but the quality of living environment is poor.

\section{MigRANT WORKERS HOUSING CHOICE ANALYSIS}

\section{A. Living Form}

According to the survey, from the living form, migrant workers living mainly in the form of rental housing and the dormitories, the rental of the most common workers to have, since the purchase of migrant workers rarely. ${ }^{[1]}$ According to this, we can see that the housing supply of migrant workers is mainly based on the market and enterprises, the government plays a very limited role.

\section{B. Living Conditions}

According to the existing survey, from the living conditions, the overall housing area of migrant workers is small, the per capita housing area is much lower than the housing area of urban residents. [2] from the point of view of internal facilities, migrant workers housing facilities, the overall level is not high, the overall housing conditions are not optimistic, some of the supporting facilities of migrant workers is also a considerable lack of. Rental housing for migrant workers to share items with other people, but also face some of the phenomenon of queuing. While living in the shed of migrant workers, the winter cold, wet summer, mosquito bites, also very hot, often become the city health of the dead. Overall, the living conditions are not optimistic.

\section{THE FACTORS AFFECTING THE WILLINGNESS OF MigRANT WORKERS HOUSING CHOICE}

\section{A. Demographic Characteristics}

Here including gender, age, marital status and educational level, residence time, the location of the residence and other characteristics of the factors. Generally, with the increase of age, migrant workers will have higher requirements for housing conditions; in the academic, migrant workers of higher education, the more hope that through their own efforts to change the status quo, to make your life better, the possibility of city house is greater; for marital status, married migrant workers more likely to buy a house than unmarried migrant workers or rent, but not to live in the unit's tendency to provide shelter; it was also found that married migrant workers with higher quality than the unmarried migrant workers housing. Residence time and the stability of the work has some impact on housing choices. Migrant workers living in the longer and the longer the unit 
working hours of migrant workers have a higher probability of purchase; the same, living and stable employment of migrant workers have a choice.

\section{B. Economic Factors}

In the choice of housing will, migrant workers consider the most is the economic factor, found in some survey of migrant workers in the cheap price is the first consideration of the majority of migrant workers housing options, followed by the convenience of the traffic away from the place of work, and finally to think is the living environment, that is to say if the price is cheap, easy to work, even if the poor conditions, for most of the migrant workers is also willing to accept. ${ }^{[3]}$ Therefore, economic factors will affect the choice of migrant workers housing will.

\section{Regional Factors}

The impact of migrant workers housing choice will be the regional factors of migrant workers mobility is relatively large. This includes two aspects, on the one hand, the work of migrant workers is not stable, with the completion of a project, the migrant workers may face losing their jobs or go to another city to work hard. On the other hand, some migrant workers or seasonal work, work out in the busy season, in the slack when working in construction, because of the mobility of migrant workers, the purchase of housing demand is not strong, but choose to rent or live in dormitories is relatively large. Therefore, the regional factors will affect the choice of migrant workers housing will.

\section{Institutional Factors}

This is a common problem for the entire migrant workers groups. Referred to the institutional factors, on the one hand is the household registration system, on the other hand is the homestead system. Household registration system is an important factor that affects the choice behavior of migrant workers' housing. Urban and rural residents as a result of identity, in many aspects of housing and other benefits of the formation of the difference is great. Migrant workers in the city to work and life, not as people have the permanent residence, but also can not be like other urban low income groups like renting low-cost housing and the purchase of affordable housing. Even if there are some high and stable income of migrant workers, in the purchase of commercial housing, but also enjoy the same treatment as the public. ${ }^{[4]}$ because of the household registration and the restriction on some policies, migrant workers do not have the ability to obtain the rights of ordinary citizens, also is not covered in the housing security system, so it is difficult for them to fight for better housing conditions. On the other hand, the majority of migrant workers in rural areas have a homestead, home for the elderly or children are mostly family, their life foundation in the countryside, only to the city work, hoping to improve the living conditions of the family, and will not give up the homestead. Therefore, institutional factors will affect the willingness of migrant workers housing choices.

\section{IMPROVE THE HOUSING SECURITY POLICY OF MIGRANT WORKERS}

Since many factors affect the choice of migrant workers housing will, we have to put forward proposals to solve. At the same time, to solve the housing problem of migrant workers is an important measure to promote the process of urbanization, in order to improve the housing security of migrant workers, this paper puts forward the following policy recommendations:

\section{A. Increase Subsidies for Migrant Workers}

Generally speaking, when people's life is still in a relatively low level, they will have to choose a suitable condition and their way of life, and to arrange and choose to live this way according to the consumer. The purchase behavior of migrant workers is affected by the urban living conditions. Therefore, in order to improve the housing conditions of migrant workers, the author believes that increasing financial subsidies to increase farmers' income is one of the effective measures. The central and local levels of government funding, according to the corresponding proportion of earmarking, raise the level of housing security of migrant workers. These funds can be divided into several parts to use, given its rental subsidies for low-income migrant workers income is not high, the most basic requirements for housing; some savings of migrant workers, in the purchase process need loans, can provide low interest loans to apply for the improvement of the housing conditions of migrant workers.

\section{B. Considering the Migrant Workers Into the Urban Housing Security System}

Studies have shown that China's migrant workers in the city has shown a long-term living situation, and the longer the migrant workers living in the city, the more likely to live long. For the migrant workers intend to leave, since the purchase is likely to become more reasonable and ideal choice. Therefore, to solve the housing problems of migrant workers, migrant workers must be in the city to provide conditions for the stability of housing and housing. First, migrant workers should be included in the housing problem of urban housing security construction planning, to relax the restrictions on migrant workers to apply for public rental housing, while increasing the construction of migrant workers apartment. Finally, the government should combine the characteristics of migrant workers and the actual situation in the region, to create a variety of forms of migrant workers housing security policy. ${ }^{[5]}$

\section{To Improve the Stability of the Work of Migrant Workers}

For migrant workers, the main source of income is the income of workers, and therefore, the work of migrant workers and their housing conditions are closely linked. Migrant workers because of educational level and work skills is relatively low, mostly engaged in heavy manual labor, low paid jobs are very common, which will limit the ability of migrant workers to improve their housing conditions in a large extent, the impact of housing choice. Therefore, the most fundamental measure to improve the 
housing conditions of migrant workers is to improve their employment ability, increase work stability, and thus can improve the income level of migrant workers, so that it has the ability to improve the living conditions.

\section{The Gradual Improvement of the Household Registration System of Migrant Workers}

The latest central document, the State Council issued the opinions on further promoting the reform of the household registration system, pointed out that the further adjustment of account migration policy. The full liberalization of towns and small city settled restraints, orderly release mediumsized city settled restrictions, reasonably determine the city settled conditions. At the same time, innovative population management, the establishment of a unified urban and rural household registration system, the establishment of a residence permit system, and improve the population information management system. In addition, but also to effectively protect the legitimate rights and interests of the transfer of agricultural population and other resident population. Improve the rural property rights system, expanding compulsory education, employment services, basic pension, basic health care, housing security and other basic public service coverage of urban and rural areas, to strengthen the financial security of basic public services. The reform of the household registration system after ${ }^{[6]}$, as one of the transfer of the agricultural population of migrant workers can enjoy some preferential policy in housing, and can reduce labor and employment, health care, housing subsidies and retirement pension and other aspects of the formation of urban residents compared with the huge difference, the urban residents enjoy equal benefits, and eliminate the cause because of illness, unemployment, pension, children's education and other aspects of the uncertainty of life risk and thus improve the menace from the rear, migrant workers housing security, and promote the process of urbanization.

\section{CONCLUSION}

The settlement of migrant workers' housing choice is a huge complex system engineering, affected by many factors, such as income, land system and social security system, and its housing demand is also different. Therefore, the housing problems of migrant workers is not a short duration of time can be completed. In the end we explore migrant workers housing choice problem, can not be generalized, according to the actual, concrete analysis of concrete problems, so as to solve the housing problems of migrant workers fundamentally.

\section{REFERENCE}

[1] Xue Jianliang, Guo Xinyu. The Housing Choice of Migrant Workers and Its Influencing Factors [J]. Agricultural Technology and Economy, 2011,12:87-93.

[2] Liu Mengqin, Fu Chen. Urban Migrant Workers Housing Problems and Reform Policies [J]. urban Observation, 2013,04:136-145.

[3] Zhang Chi. Housing Choice Behavior and its Influencing Factors of migrant Workers in Beijing City [J]. Building Economy, 2010,01:5-8.
[4] Zhang Yu. A Review of the Theory of Urban Housing for Migrant Workers in Urban Housing Research [J]. Theory, 2015,16:120-121.

[5] Wang Kai, Hou Aimin, Zhai Qing. The Research Summary of the Housing Problem of Urban Migrant Workers [J]. City Development City Housing Problems of Migrant Workers, 2010, 01:118-122.

[6] State Council on Further Promoting the Reform of the Household Registration System [J]. Urban Planning Advice, 2014,15:1-3. 